\title{
Dual Input Z-source Indirect Matrix Converter for Grid Connected Hybrid Renewable Energy Systems
}

\author{
Yazid Berkani ${ }^{1 *}$, Nabil Taib ${ }^{1}$ \\ ${ }^{1}$ Laboratoire de Technologie Industrielle et de I'Information, Faculté de Technologie, Université de Bejaia, 06000 Bejaia, Algeria \\ * Corresponding author, e-mail: berkaniyazid@gmail.com
}

Received: 11 February 2021, Accepted: 20 March 2021, Published online: 21 June 2021

\begin{abstract}
This paper presents a new converter topology for grid connected Hybrid Renewable Energy System (HRES). The proposed topology named Dual Input Z-source Indirect Matrix Converter (DIZIMC) consists of an Ultra Sparse Z-source Matrix Converter (USZMC) interfacing PV and Wind Turbine (WT) to the grid. The DC link of the proposed converter is replaced by Interconnection Sources System (ISS). The ISS operates according to whether the sources produce energy or not. It allows connecting the sources individually or simultaneously and even isolates them if necessary. In the other hand, the DIZIMC provides several advantages such as reduced number of IGBTs and compact size inherited from USZMC, the use of Z-sources instead of conventional DC/DC converters keep the matrix configuration of the global structure. The global model of the proposed system was tested by simulation under Matlab/ Simpowersys environment. The obtained results show clearly freedom in connecting the operational sources, also a better quality of energy injected to the grid.
\end{abstract}

\section{Keywords}

dual input converter, ultra sparse matrix converter, z-source matrix converter, hybrid renewable energy system

This article was originally published with an error. This version has been corrected/amended in the Corrigendum. Please see the Corrigendum (https://doi.org/10.3311/PPee.18966)!

\section{Introduction}

The perpetual demand for energy is tremendously increased to meet the daily needs of the human being. Nevertheless, the conventional resources used are exhaustible and impact negatively on the environment ecosystem, known as global warming which threats all forms of life on the planet. In this sense, the world converges towards the use of renewable energies which are not only available and inexhaustible but also inhibit the emitting of $\mathrm{CO} 2$ gas. However, these non-conventional resources are naturally intermittent depending on diverseness of climatic conditions, so that, these sources were emerged under a Hybrid Renewable Energy System (HRES).

According the literature review, several studies have been done on HRES whether connected to the grid $[1,2]$ or standalone with storage systems [3-5], aimed to enhance the performance of HRES by extracting maximum power using Maximum Power Point Tracking (MPPT) algorithms such as fuzzy logic [4] and Artificial Neural Network MPPT algorithms [1]. The authors [3, 4], have proposed different power management strategies applied to stand-alone hybrid power system enabling the continuity of energy flow.
A Multi-Objective Particle Swarm Optimization algorithm is used [6] for an optimal design of multi-source hybrid system to improve its efficiency by minimizing cost and the total losses.

The development of power electronics has significantly contributed for a better integration and exploitation of HRES as well as on the quality of the energy produced as dictated by international standard [7].

Since the apparition of matrix converters, numerous published papers were increasingly carried [8-17], which substantiates their importance and their benefits that provide. Their integration in renewable energies systems provides interesting advantages. The elimination of the DC link capacitor for energy storage offers a small structure and improves reliability [10]. The authors [11] have proposed an application of direct matrix converter in a wind turbine associated with a flywheel energy storage system. A three level sparse topology has been used in wind generation in [12], derived from the indirect matrix converter with a reduced number of switches. 
In the other hand, the disadvantage of matrix converters lies on the transformation ratio that does not exceed 0.866 . To overcome this problem two solutions are possible. The first is software method which consists to use the over-modulation strategies [13]. The second method is a hardware solution that called Hybrid matrix converter by adding an auxiliary converter as an H-bridge inverter [14], an auxiliary voltage source [15] and a combination of $Z$-source with the matrix converter which called Z-source matrix converter [16-18].

The paramount challenges hinder the HRES are to improve performance and reduce cost by minimize number of power converters used, guaranteeing insensitivity to variations of voltages sources. So, another type of converter has appeared in order to reduce the number of DC/ DC converters used in HRES by increasing the number of inputs named Multi-Input DC/DC Converter (MIC) [19]. The MICs are designed to reduce the cost and size of HRES, centralized control and high efficiency. The MICs are equipped with DC/DC converter cells and can operate in different mode buck, boost or buck-boost. There are two main topologies of MICs: isolated [20] and non-isolated DC/DC MICs [21-23]. The size of isolated DC/DC MIC is bigger than non-isolated multi-input $\mathrm{DC} / \mathrm{DC}$ converter due to magnetic circuit used to decouple the inputs from the output. However, in non-isolated multi-input DC/DC converter the coupling is electrically.

In this paper, a new converter topology for grid connected HRES is presented. This topology aims to reduce size and cost by reducing number of power switches. The proposed converter allows connecting AC and DC sources to the grid through a Dual Input Z-source Indirect Matrix Converter
(DIZIMC) as shown Fig. 1. The DC link of the proposed converter is replaced by an ISS. This last is based on matrix converter fundamentals that connects any input sources to the inverter side, besides offering a degree of freedom in case of post fault operation. In order to preserve matrix structure, Z-sources are used instead of DC/DC converters.

The framework of this paper encompasses the following elements: in Section 2, each parts of the studied system are displayed. Section 3 describes the different ISS operations modes. Then, Section 4 unveils Z-source converter and shows its operating mode. Section 5 offers the control strategy of the proposed DIZIMC. Furthermore, Section 6 discusses the simulation results. Finally, Section 7 recapitulates the conclusions determined of this paper.

\section{Studied system description}

The main structure of the studied system is presented in Fig. 2 where the proposed DIZIMC is integrated. The AC and DC sources consist of wind generator based on a permanent magnet synchronous generator (PMSG) and PV generator respectively. The model of WT generator used is given in $[4,24]$, while that of PV generator is that given in [2-4].

DIZIMC formed with ultra-sparse rectifier stage which converts the AC voltage source to DC voltage. To balance the resulting DC voltage and that of PV generator,

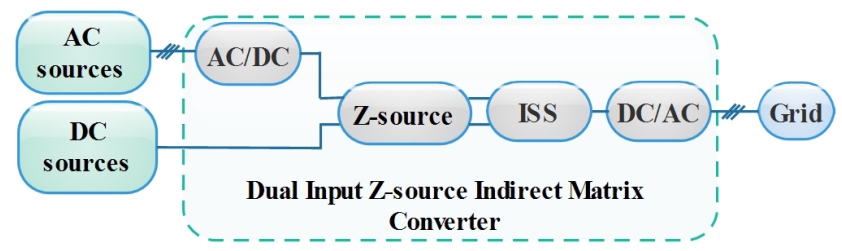

Fig. 1 Block diagram of the proposed system

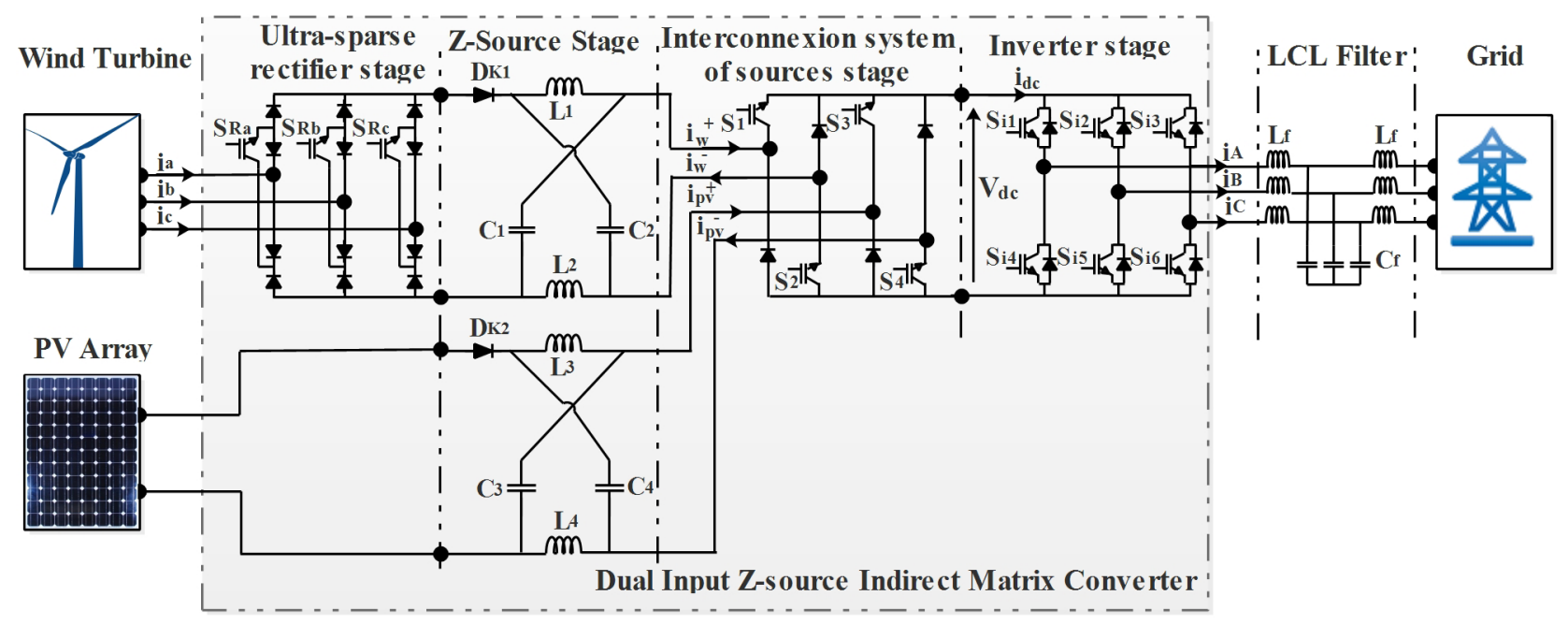

Fig. 2 Hybrid Renewable Energy System including the DIZIMC 
two Z-sources are inserted. In order to connect these two DC voltage sources simultaneously or individually to the two-level inverter stage, an ISS based on power switches is added to DC link voltage. An LCL filter is inserted between the grid and the two-level inverter stage.

\section{Analysis and operation of the ISS}

The basic idea of the ISS is to connect any input voltage sources to the output side, inspired from matrix converter principles. The ISS allows connecting two sources to DC bus, simultaneously or individually, even isolates them if necessary. It can also be expanded to several energy sources and the insert of storage elements is viable. The ISS composed by four IGBTs and four diodes as it is depicted in Fig. 3.

The full operating modes of the proposed ISS are detailed bellow.

- Mode 1: when the renewable resources are not sufficient to product the electrical energy, the both must be isolated. To this end, all IGBTs should be OFF as it is shown in Fig. 3(a).

- Mode 2: when only the WT is producing electrical energy, it should be connected individually. So, only the IGBTs $S_{1}$ and $S_{2}$ are fired and all diodes are blocked as it is shown in Fig. 3(b).

- Mode 3: in this case where only PV array is producing electrical energy, it should be connected individually. Thus, only IGBTs $S_{3}$ and $S_{4}$ are fired and all diodes are reverse biased, as it is illustrated in Fig. 3(c).

- Mode 4: when both sources are producing electrical energy, they must be connected simultaneously by firing all IGBTs. In this case, all diodes are blocked as it is illustrated in Fig. 3(d).

It is to note that the diodes are inserted in this structure to avoid short circuit of DC voltage sources.

The mathematical model of ISS is presented by matrix below:

$$
\left(\begin{array}{l}
i_{d c}^{+} \\
i_{d c}^{-}
\end{array}\right)=\left(\begin{array}{llll}
K_{1} & 0 & K_{3} & 0 \\
0 & K_{2} & 0 & K_{4}
\end{array}\right) \cdot\left(\begin{array}{c}
i_{w}^{+} \\
i_{w}^{-} \\
i_{p v}^{+} \\
i_{p v}^{-}
\end{array}\right) .
$$

$i_{p v}$ and $i_{w}$ are DC currents generated by PV array and WT respectively, $i_{d c}$ is the ISS output DC current and $K_{1}$ to $K_{4}$ are the control signals of IGBTs $S_{1}$ to $S_{4}$, respectively.

The ISS depends on whether the sources produce energy or not. The flowchart of the control strategy of ISS is shown in Fig. 4.
Foremost, the generated of voltage and current of PV array and those generated by WT are measured. Then, the powers produced by both sources are calculated. If the both sources are producing power $K_{1}$ to $K_{4}$ are equal to 1 . If only WT is producing power $K_{1}=K_{2}=1$ and $K_{3}=K_{4}=0$. If only $\mathrm{PV}$ array is producing power $K_{1}=K_{2}=0$ and $K_{3}=K_{4}=1$. Else if the both sources are not sufficient to product the electrical energy $K_{1}$ to $K_{4}$ are equal to 0 .

\section{Z-source inverter}

The combination of DC/DC converter and inverter provides a high $\mathrm{AC}$ voltage output rather than a conventional inverter. Thus, more natural way through a specific
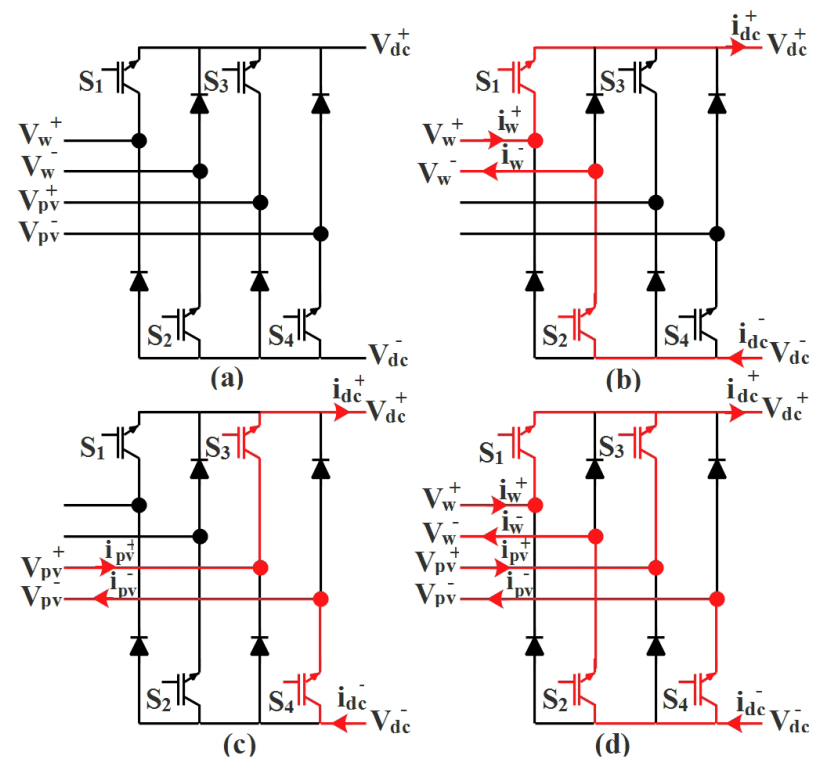

Fig. 3 The operating modes of the ISS; (a) No sources, (b) Only WT, (c) Only PV array, (d) PV and WT simultaneously

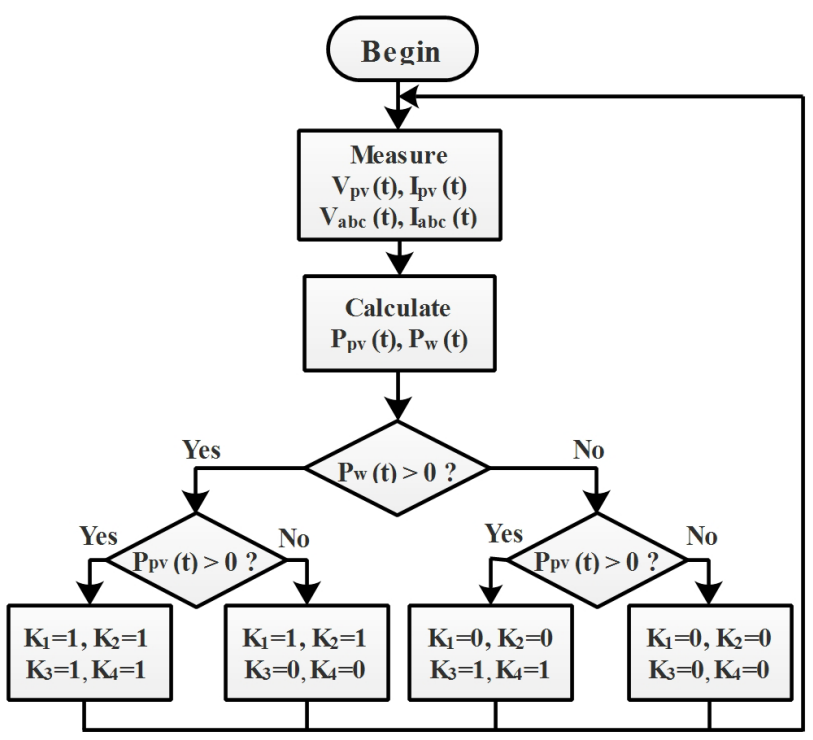

Fig. 4 Flowchart of ISS control strategy 
command and replacing the DC/DC converter by a network impedance of LC type arranged in "X", called Z-source inverter [25, 26], as it is illustrated in Fig. 5.

It uses the switches of the inverter to adjust the voltage of the DC link bus $V_{d c}$, accordingly the control of the inverter is slightly modified by introducing short circuit moments of one or more arms of the inverter which are realized during the freewheel phases of the inverter. The active states of the inverter remain unchanged. The network impedance of the Z-source have a symmetrical structure where $C_{1}=C_{2}=C$ and $L_{1}=L_{2}=L$ which implies that the voltages across the capacitors and inductors are identical $V_{C 1}=V_{C 2}=V_{C}, V_{L 1}=V_{L 2}=V_{L}$, also the currents in the inductors $i_{L 1}=i_{L 2}=i_{L}$.

Let $\hat{V}_{d c}$ be the maximum input voltage of the inverter, the $\hat{V}_{M}$ maximum output voltage of the inverter. The modulation index $m$ is defined by Eq. (2):

$m=\frac{2 \hat{V}_{M}}{\hat{V}_{d c}}$.

The amplification of the DC stage $b$ is defined by Eq. (3):

$b=\hat{V}_{d c} / V_{\text {in }}$,

where $V_{\text {in }}$ is the input DC voltage of the Z-source stage.

Three operation modes are distinguished. The first mode, active states of the inverter are applied and the diode $D_{K}$ is forward biased. So, the inverter is seen from the $\mathrm{Z}$-source as a current source. From equivalent circuit in Fig. 6(a), one has:

$V_{L}=V_{i n}-V_{C}$,

$V_{d c}=V_{C}-V_{L}=2 \times V_{C}-V_{\text {in }}$

The second mode, $D_{K}$ is $\mathrm{ON}$ and zero states of the inverter are applied i.e., freewheeling operation. Hence, the inverter is seen from the Z-source as an open circuit as it is shown in Fig. 6(b). In the last mode, as it is shown in Fig. 6(c), $D_{K}$ is reverse biased and an arm of the inverter is short-circuited, which implies a zero voltage output of the Z-source continuous stage, one has:

$V_{L}=V_{C}$,

$V_{d c}=0$.

According to Eqs. (4) and (6), the average voltage across the inductance over one switching period is given by Eq. (8):

$<V_{L}>=\frac{T_{z} \times V_{C}+T_{1} \times\left(V_{i n}-V_{C}\right)}{T_{s}}=0$.

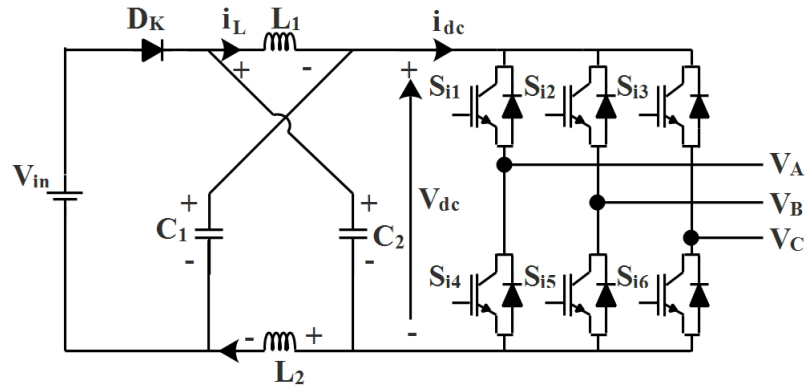

Fig. 5 Z-source inverter structure

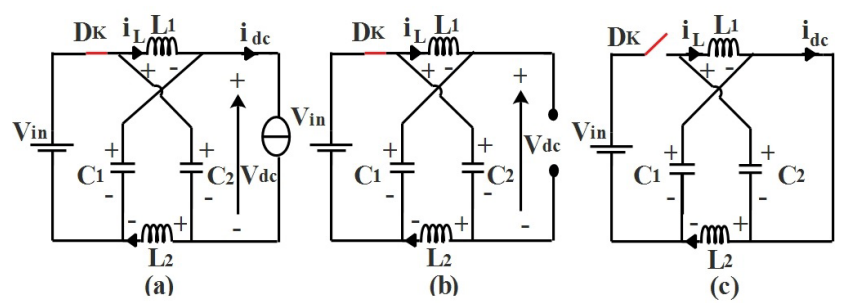

Fig. 6 Equivalent circuit of the Z-source in different operation modes; (a) mode 1; (b) mode 2; (c) mode 3

With, $T_{S}=T_{1}+T_{Z}, T_{1}$ time of the active states of the inverter and $T_{Z}$ time of the shoot through.

Rearranging the equation above gives Eq. (9):

$\frac{V_{C}}{V_{\text {in }}}=\frac{T_{1}}{T_{1}-T_{z}}$

The voltages across the capacitors can be calculated from Eq. (9) as follows:

$V_{C_{1}}=V_{C_{2}}=V_{C}=\frac{T_{1}}{T_{1}-T_{z}} V_{\text {in }}$.

According to Eqs. (5), (7) and (10), the average input voltage of the inverter over one switching period is calculating by Eq. (11):

$<V_{d c}>=\frac{T_{z} \times 0+T_{1} \times\left(2 \times V_{C}-V_{i n}\right)}{T_{s}}=\frac{T_{1}}{T_{1}-T_{z}} V_{i n}=V_{C}$.

According to Eqs. (3) and (5), the maximum input voltage of the inverter can be written as follows:

$\hat{V}_{d c}=V_{C}-V_{L}=2 \times V_{C}-V_{i n}=\frac{T_{s}}{T_{1}-T_{z}} V_{i n}=b \times V_{i n}$.

From Eq. (12), the amplification ratio of the continuous stage is equal to:

$b=\frac{T_{s}}{T_{1}-T_{z}}=\frac{1}{1-2 \times \frac{T_{z}}{T_{s}}}=\frac{1}{1-2 \times d_{z}} \geq 1$. 


\section{Control strategy of DIZIMC}

DIZIMC is composed of an ultra sparse Z-source matrix converter combined with the Interconnection Sources System. Hence, the control of the proposed DIZIMC is reduced to the control of USZMC because the control of ISS, detailed in Section 3, depends on whether the sources produce energy or not.

It is well known that the Space Vector Modulation (SVM) is the suitable control strategy for the matrix converter topologies because of its numerous advantages such as a better waveforms quality. This is why it is chosen as modulation strategy for the USZMC.

To apply the SVM method, the input currents of the rectifier stage and the output voltage of the inverter stage reference vectors must be constructed. Their expressions, derived from Fig. 7, are given by Eqs. (14) and (15):

$$
\begin{gathered}
I_{\text {ref }}=\left(\frac{2}{3}\right)\left(i_{a}+\exp \left(j \frac{2 \pi}{3}\right) i_{b}+\exp \left(j \frac{4 \pi}{3}\right) i_{c}\right), \\
V_{\text {ref }}=\frac{2}{3}\left(v_{A}+\exp \left(j \frac{2 \pi}{3}\right) v_{B}+\exp \left(j \frac{4 \pi}{3}\right) v_{C}\right) .
\end{gathered}
$$

\subsection{USZMC rectifier stage control}

In order to control the USZMC rectifier stage, the vector expressed by Eq. (14) is used. The projection of this vector on the two axes of the sector where it is located leads to generate the applied control vectors (two active and one null vectors) as it is shown in Fig. 7(a). These vectors will be applied during a duty cycles, $d_{\nu}, d_{\delta}$ for active vectors and $d_{0 i}$ for the null vector, respectively, defined by Eqs. (16), (17) and (18):

$$
\begin{aligned}
& d_{\gamma}=m_{i} \sin \left(\frac{\pi}{3}-\theta_{i}\right), \\
& d_{\delta}=m_{i} \sin \left(\theta_{i}\right), \\
& d_{0 i}=1-d_{\delta}-d_{\gamma} .
\end{aligned}
$$

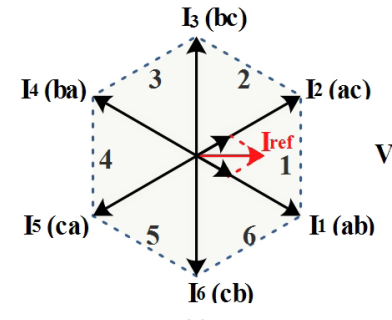

(a)

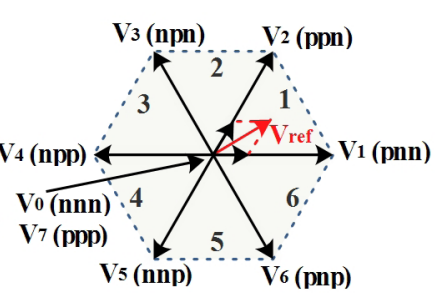

(b)
Fig. 7 (a) Input current hexagon, (b) Output voltage hexagon
Where: $\theta_{i}$ is the angle of the reference space vector of the input current belongs to $[0, \pi / 3]$ with respect to the lower axis of the actual sector, $m_{i}=1$ is the modulation index of the rectifier stage.

The null vector produced by the rectifier stage can be eliminated due to the redundancy with that inverter stage. Therefore, the switching sequence of the rectifier stage consists only of two adjacent current vectors. The duty cycles $d_{\gamma}$ and $d_{\delta}$ are rescaled as follows [14]:

$$
\begin{aligned}
& d_{\gamma}^{R}=\frac{d_{\gamma}}{d_{\gamma}+d_{\delta}}, \\
& d_{\delta}^{R}=\frac{d_{\delta}}{d_{\gamma}+d_{\delta}} .
\end{aligned}
$$

Since the ultra-sparse matrix converter has just one IGBT and four diodes on one arm of the rectifier compared to the conventional indirect matrix converter four IGBTs and four diodes (Fig. 8). The control signals $S_{R 1}$ and $S_{R 2}$ are combined by the logical function "OR" to generate the control signal of the single IGBT $S_{R a}$.

\subsection{USZMC inverter stage control}

The control of the USZMC inverter stage is derived from the reference voltage space vector expressed by Eq. (15). The applied control vectors and their corresponding duty cycles are synthesized by the same way as that used for the reference current space vector. However, the null vectors will be used in this stage. It is well known that, in the case of a two-level inverter, there is eight possible switching states, six active vectors $\left(\boldsymbol{V}_{1}, \boldsymbol{V}_{6}\right)$ and two null vectors $\boldsymbol{V}_{0}$ and $\boldsymbol{V}_{7}$ (Fig. 7(b)). Only two active and one null vector will be used in a single switching period. The corresponding duty cycles, $d_{\alpha}$ and $d_{\beta}$ for the active and $d_{0}$ for the null vectors, are computed using Eqs. (21), (22) and (23):

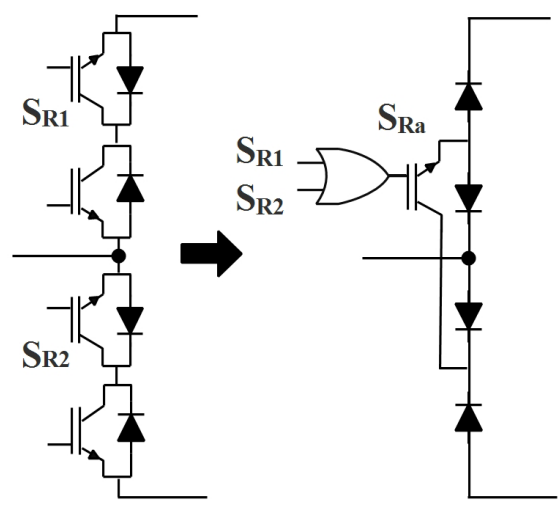

Fig. $8 \mathrm{An}$ arm of the rectifier stage: in the left indirect matrix converter, in right ultra-sparse matrix converter 
$d_{\alpha}=m_{v} \sin \left(\frac{\pi}{3}-\theta_{v}\right)$

$d_{\beta}=m_{v} \sin \left(\theta_{v}\right)$,

$d_{0}=1-d_{\alpha}-d_{\beta}$,

where the modulation index $m_{v}$ expression of inverter stage is given by Eq. (24):

$m_{v}=\frac{\sqrt{3}}{V_{d c}} V_{s}$,

where $\theta_{v}$ is the angle of the space vector of the output voltage belongs to $[0, \pi / 3]$ with respect to the lower axis of the sector, $V_{d c}$ is the DC link bus voltage, $V_{s}$ is output voltage of the inverter.

A slight modification in the duty cycle of the null vector of the USZMC inverter stage should be done. This modification consists of introducing shoot through duty cycle $d_{z}$, resulting by the inserted Z-source at the DC-link bus, in the control of the inverter stage expressed by Eq. (25) derived from Eq. (13).

$d_{z}=\frac{b-1}{2 b}$

The new expression of $d_{0}$ is given by Eq. (26):

$d_{0}=1-d_{\alpha}-d_{\beta}-d_{z}$.

\subsection{Switching sequence of USZMC}

To synthesize the control of USZMC, switching sequences of both rectifier and inverter stages are used. After calculating the duty cycles of rectifier stage and those of inverter stage, a double sided symmetrical switching sequence is applied at each $T_{s}$. The resulting switching sequence should have a minimum switching number. One can be note that there are thirty six possible switching sequences which can be applied to USZMC. Here, one situation is taken as an example to explain the switching sequence construction process.

Considering that the both current and voltage reference vectors are lying in sector 1 , vectors $\boldsymbol{I}_{1}$ and $\boldsymbol{I}_{2}$ will be applied to the rectifier stage during duty cycles $d_{\gamma}{ }^{R}$ and $d_{\delta}^{R}$, respectively, the switching sequence will be $\boldsymbol{I}_{1}-\boldsymbol{I}_{2}-\boldsymbol{I}_{1}$. For the inverter stage, vectors $\boldsymbol{V}_{1}, \boldsymbol{V}_{2}, \boldsymbol{V}_{0}$ and $\boldsymbol{V}_{z}$ will be applied during duty cycles $d_{\alpha}, d_{\beta}, d_{0}$ and $d_{z}$, respectively, and the switching sequence will be $\boldsymbol{V}_{1}-\boldsymbol{V}_{2}-\boldsymbol{V}_{1}-\boldsymbol{V}_{0}-\boldsymbol{V}_{z}-\boldsymbol{V}_{0}-\boldsymbol{V}_{1}-\boldsymbol{V}_{2}-\boldsymbol{V}_{1}$, as it is summarized in Fig. 9.

\section{Simulation results and discussions}

In this section, the performances of the proposed system are analyzed by simulation under the Matlab/Simpowersys environment. The simulation parameters of the system are shown in Appendix.

It is well known that the renewable sources have a random behavior because of climatic conditions. In the aim to test the performances of the proposed structure, a scenario including all possible situations should be defined. To this end, the chosen scenario is as follows: from $0.4 \mathrm{~s}$ to 1.1 $\mathrm{s}$ PV array is generating power. WT is generating power from $0 \mathrm{~s}$ to $0.28 \mathrm{~s}$ and from $0.6 \mathrm{~s}$ to $1.1 \mathrm{~s}$. From $0.28 \mathrm{~s}$ to 0.4 $\mathrm{s}$ and from $1.1 \mathrm{~s}$ to $1.2 \mathrm{~s}$ no power is produced.

Fig. 10 represents the control signals of the ISS switches based on the scenario defined previously.

The average active power $P_{w}$ and average reactive power $Q_{w}$ of the PMSG are shown in Fig. 11. The reactive power is not null because any control strategy is applied to the PMSG of this system.

Average output power of the ISS $P_{i n v}$ which is the input power of the inverter and the average inputs power of the ISS which are the power generated by PV array $P_{p v}$ and the output power of the rectifier $P_{w t}$ are depicted in Fig. 12.

As it can be seen in this latter, from $0 \mathrm{~s}$ to $0.28 \mathrm{~s}$ only WT is generating power. In this mode, the WT is the only source connected by the ISS. When no source delivers power from $0.28 \mathrm{~s}$ to $0.4 \mathrm{~s}$, ISS isolates the both sources

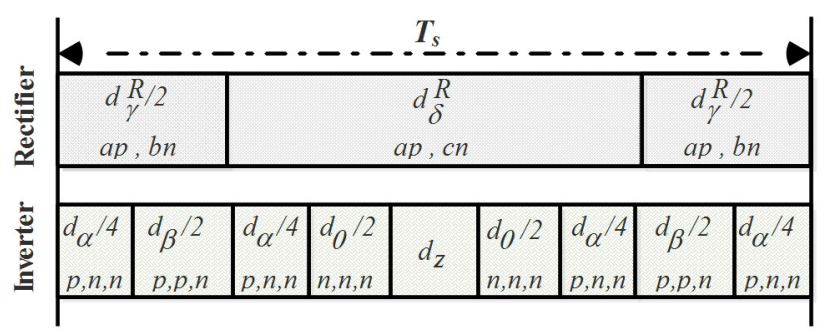

Fig. 9 Switching sequence of the inverter stage and the rectifier stage for reference vectors locating in sector 1

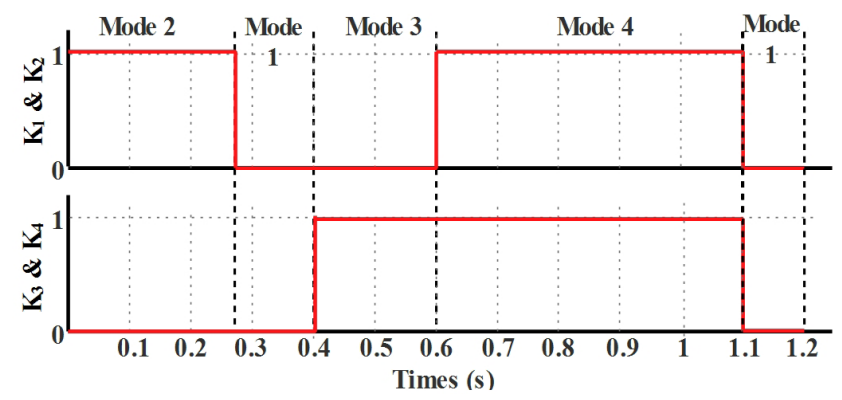

Fig. 10 Control signals of the ISS 
from the grid and the inverter is OFF because there is no power to inject to the grid. From $0.4 \mathrm{~s}$ to $0.6 \mathrm{~s}$, only PV array is generating power. The ISS connects it individually. When both sources simultaneously are generating power from $0.6 \mathrm{~s}$ to $1.1 \mathrm{~s}$, in this case ISS connects them simultaneously and both $P_{p v}$ and $P_{w t}$ are injected to the grid. Finally, since no source delivers power between $1.1 \mathrm{~s}$ and $1.2 \mathrm{~s}$, the ISS disconnects the both sources.

Regarding the power injected to the grid, the displacement of the grid currents and voltages should be inspected. The injected current to the grid is in opposit phase with its corresponding voltage, as it is illustrated in Fig. 13. This means that the produced active power $P_{g}$ is injected to the grid. This opposition phase appears more clearly when the two sources are connected simultaneously. When the system operates in post fault i.e., only one source is connected, the obtained results show that the power factor is not equal to -1 , this is why the grid provides a reactive power $Q_{g}$. However, $Q_{g}$ is compensated, without using any power control at the grid side, when the both sources are connected simultaneously as it is illustrated in Fig. 14. A power analysis is done in every part of the system in the stable range of power generators and summarized in Table 1.

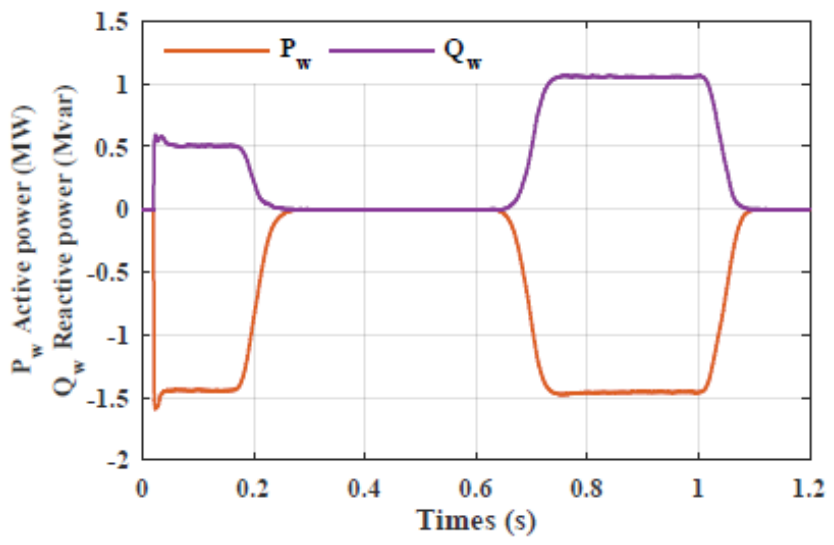

Fig. 11 Active and reactive powers of the PMSG

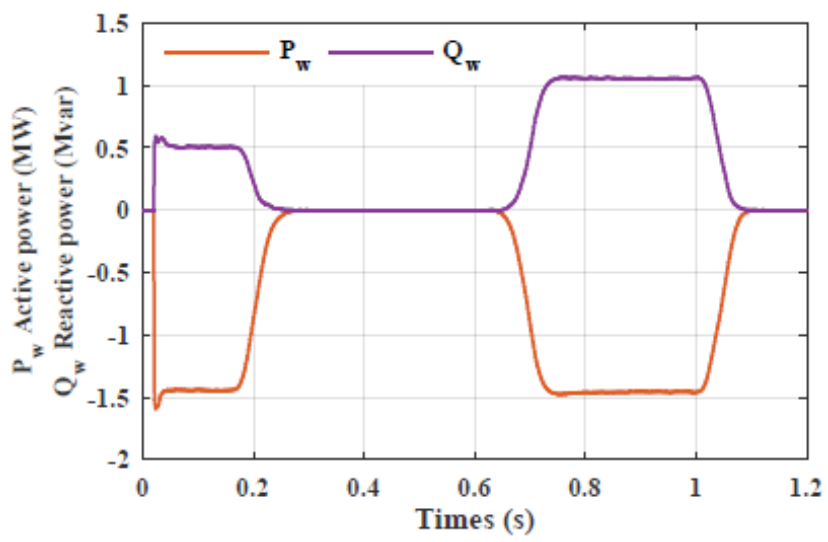

Fig. 12 Output power of the ISS

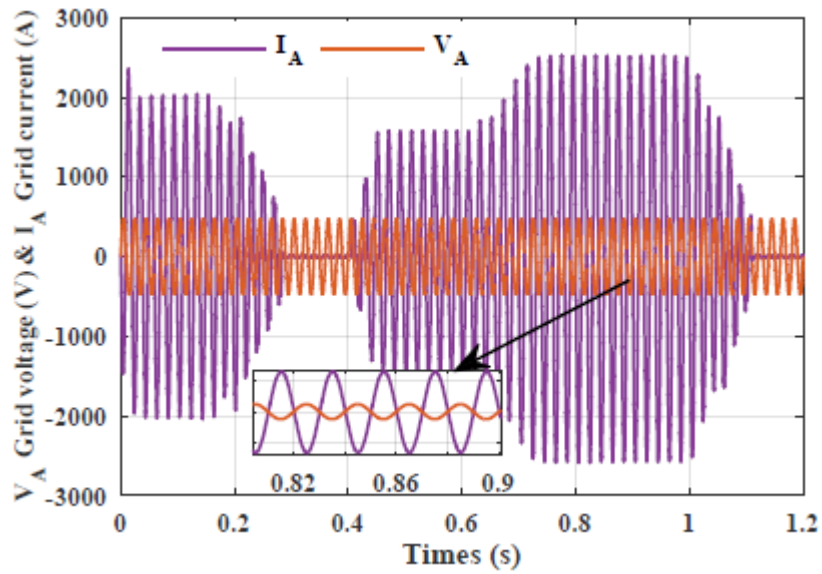

Fig. 13 Voltage and current of the grid

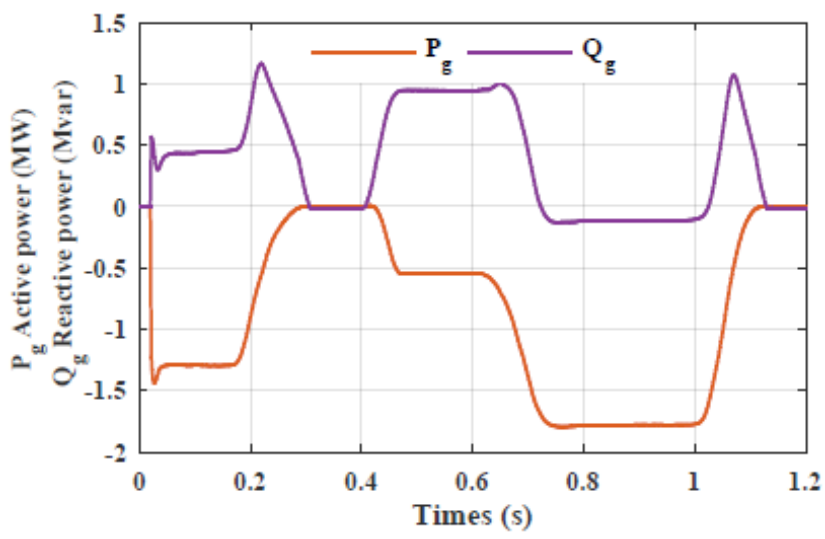

Fig. 14 Active and reactive powers grid side

Table 1 Power analysis

\begin{tabular}{lccccc}
\hline Times (s) & $0-0.28$ & $0.28-0.4$ & $0.4-0.6$ & $0.6-1.1$ & $1.1-1.2$ \\
\hline$P_{w}(\mathrm{MW})$ & -1.44 & 0 & 0 & -1.46 & 0 \\
$Q_{w}$ (Mvar) & 0.506 & 0 & 0 & 1.065 & 0 \\
$P_{p v}(\mathrm{MW})$ & 0 & 0 & 0.616 & 0.55 & 0 \\
$P_{w t}(\mathrm{MW})$ & 1.405 & 0 & 0 & 1.43 & 0 \\
$P_{i n v}(\mathrm{MW})$ & 1.375 & 0 & 0.596 & 1.927 & 0 \\
$P_{g}(\mathrm{MW})$ & -1.291 & 0 & -0.545 & -1.78 & 0 \\
$Q_{g}(\mathrm{Mvar})$ & 0.436 & 0 & 0.945 & -0.112 & 0 \\
\hline
\end{tabular}

In order to analyze the quality of the grid power injected, a spectral analysis of the currents injected to the grid is performed. When both sources are connected, the THD value of the grid current is $1.64 \%$, as it is shown in Fig. 15. Fig. 16 represents the THD value of the current injected by the WT that is equal to $2.43 \%$. In the case where only PV array is connected to the grid, THD value of injected current is equal to $3.41 \%$ as it is shown Fig. 17 . One can be conclude from the obtained THD values that the international standards are respected since they are lower than $<5 \%$. 


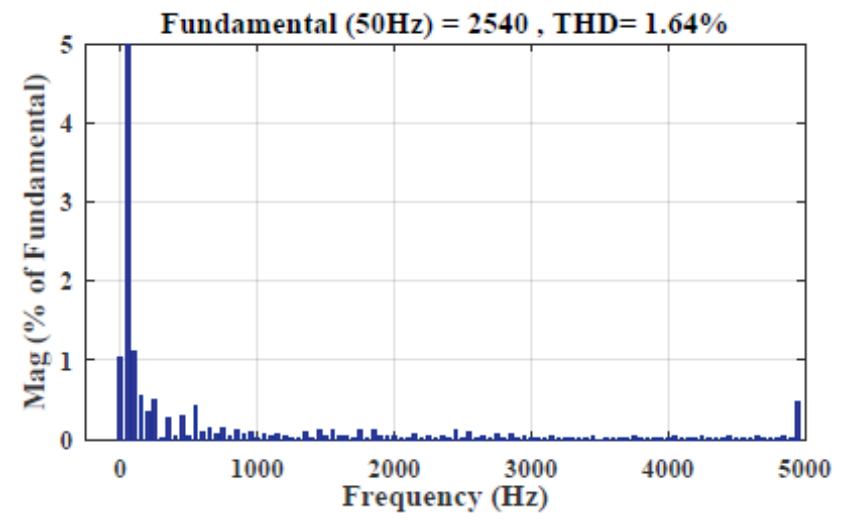

Fig. 15 Spectral analysis of the grid current when both sources are connected

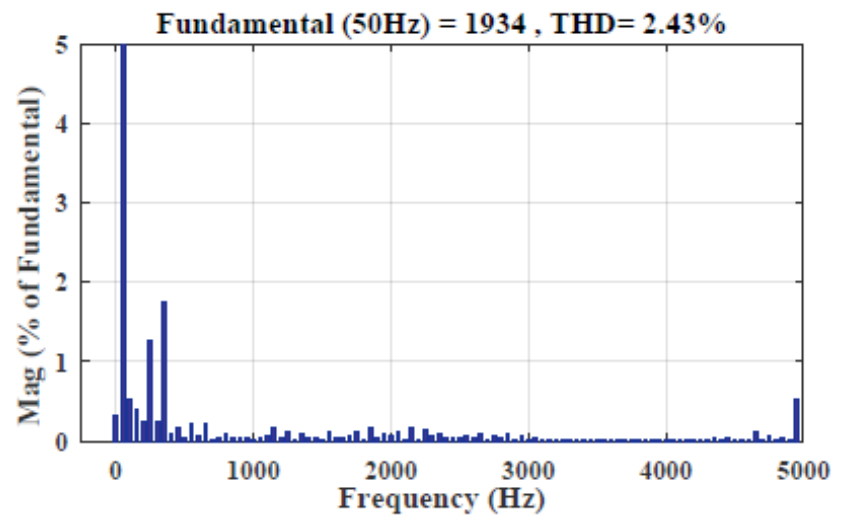

Fig. 16 Spectral analysis of the grid current when only WT is connected

\section{Conclusion}

In this paper, dual input z-source indirect matrix converter for hybrid PV-wind turbine grid connected generator is presented. The proposed converter structure allows connecting both sources, individually or simultaneously depending on whether the sources produce

\section{References}

[1] Jayaraju, G., Rao, G.S. "A new optimized ANN algorithm based single phase grid connected PV-wind system using single switch high gain DC-DC converter", European Journal of Electrical Engineering, 21(4), pp. 373-381, 2019.

https://doi.org/10.18280/ejee.210405

[2] Toual, B., Mokrani, L., Kouzou, A., Machmoum, M. "Power Quality and Capability Enhancement of a Wind-Solar-Battery Hybrid Power System", Periodica Polytechnica Electrical Engineering and Computer Science, 64(2), pp. 115-132, 2020.

https://doi.org/10.3311/ppee.14437

[3] Koulali, M., Mankour, M., Negadi, K, Mezouar, A. "Energy management of hybrid power system PV Wind and battery based three level converter", TECNICA ITALIANA-Italian Journal of Engineering Science, 63(2-4), pp. 297-304, 2019.

https://doi.org/10.18280/ti-ijes.632-426

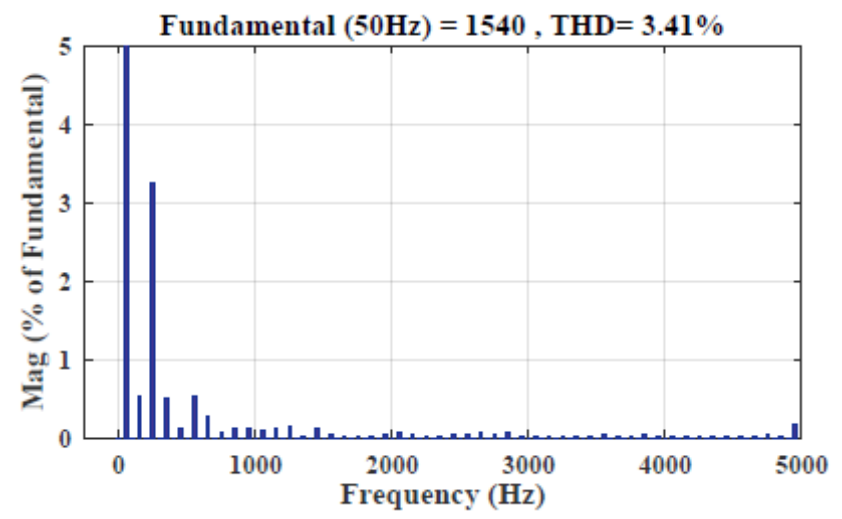

Fig. 17 Spectral analysis of the grid current when only PV array is connected

energy or not and even isolates them if necessary, to the grid thanks to an Interconnection Sources System. The ISS seems as DC/DC converter. The ultra-sparse rectifier and the $\mathrm{Z}$-sources are chosen to allow the use of the ISS. The resulting structure (DIZIMC) provides many advantages such as the reduced number of controlled switches, elimination of DC/DC converters already proposed in the literature and the compact sight of the proposed converter topology.

Moreover, the proposed converter topology was tested by simulation with the hybrid generator system under different situations of the sources. The simulation results highlighted a noticeable freedom in connecting the operational sources during a defined scenario. Also, the better quality of the injected energy to the grid in term of THD falling within the range imposed by international standards without using power control techniques neither grid side nor generator side.

[4] Koulali, M., Berkani, A., Negadi, K., Mankour, M., Mezouar, A. "Sliding fuzzy controller for energy management of residential load by multi-sources power system using wind PV and battery", Journal Européen des Systèmes Automatisés, 53(3), pp. 305-315, 2020. https://doi.org/10.18280/jesa.530301

[5] Aissou, S., Rekioua, D., Mezzai, N., Rekioua, T., Bacha, S. "Modeling and control of hybrid photovoltaic wind power system with battery storage", Energy Conversion and Management, 89, pp. 615-625, 2015. https://doi.org/10.1016/j.enconman.2014.10.034

[6] Suchitra, D., Jegatheesan, R., Deepika, T. J. "Optimal design of hybrid power generation system and its integration in the distribution network", International Journal of Electrical Power \& Energy Systems, 82, pp. 136-149, 2016. https://doi.org/10.1016/j.ijepes.2016.03.005 
[7] "IEEE Application Guide for IEEE Std 1547(TM), IEEE Standard for Interconnecting Distributed Resources with Electric Power Systems", IEEE Std 1547.2-2008, pp. 1-217, 15 April 2009. https://doi.org/10.1109/ieeestd.2008.4816078

[8] Moati, Y., Kouzi, K. "Investigating the Performances of Direct Torque and Flux Control for Dual Stator Induction Motor with Direct and Indirect Matrix Converter", Periodica Polytechnica Electrical Engineering and Computer Science, 64(1), pp. 97-105, 2020.

https://doi.org/10.3311/ppee.14977

[9] Alammari, R., Aleem, Z., Iqbal, A., Winberg, S. "Matrix converters for electric power conversion: Review of topologies and basic control techniques", International Transactions on Electrical Energy Systems, 29(10), pp. e12063, 2019. https://doi.org/10.1002/2050-7038.12063

[10] Taib, N., Metidji, B., Rekioua, T., Francois, B. "Novel low-cost self-powered supply solution of bidirectional switch gate driver for matrix converters", IEEE Transactions on Industrial Electronics, 59(1), pp. 211-219, 2011. https://doi.org/10.1109/tie.2011.2165193

[11] Ghedamsi, K., Aouzellag, D. "Improvement of the performances for wind energy conversions systems", International Journal of Electrical Power \& Energy Systems, 32(9), pp. 936-945, 2010. https://doi.org/10.1016/j.ijepes.2010.02.012

[12] Taib, N., Metidji, B., Rekioua, T. "Performance and efficiency control enhancement of wind power generation system based on DFIG using three-level sparse matrix converter", International Journal of Electrical Power \& Energy Systems, 53, pp. 287-296, 2013. https://doi.org/10.1016/j.ijepes.2013.05.019

[13] Chiang, G. T., Itoh, J. I. "Comparison of two overmodulation strategies in an indirect matrix converter", IEEE Transactions on Industrial Electronics, 60(1), pp. 43-53, 2012. https://doi.org/10.1109/tie.2012.2185021

[14] Klumpner, C., Pitic, C. "Hybrid matrix converter topologies: An exploration of benefits", In: 2008 IEEE Power Electronics Specialists Conference, Rhode, 2008, pp. 2-8. https://doi.org/10.1109/pesc.2008.4591887

[15] Wijekoon, T., Klumpner, C., Zanchetta, P., Wheeler, P.W. "Implementation of a hybrid AC-AC direct power converter with unity voltage transfer", IEEE Transactions on power electronics, 23(4), pp. 1918-1926, 2008. https://doi.org/10.1109/tpel.2008.924601

[16] Ellabban, O., Abu-Rub, H., Bayhan, S. "Z-Source matrix converter: An overview", IEEE Transactions on Power Electronics, 31(11), pp. 7436-7450, 2016.

https://doi.org/10.1109/tpel.2015.2471799

\section{Appendix}

PMSG parameters: rated power $P_{w}=1.5 \mathrm{MW}$; rated frequency $f=50 \mathrm{~Hz}$; rated torque $T=229.18 \mathrm{kN} . \mathrm{m}$; rated speed $\Omega=6.5450 \mathrm{rad} / \mathrm{s} ; p=48 ; R=0.006 \Omega ; L_{a}=L_{d}=0.000395 \mathrm{H} ;$ $J=350 \mathrm{~kg} . \mathrm{m}^{2} ; f_{r}=0.01$ N.m.s; $\lambda=1.48$ V.s.

PV Array: Module 1Soltech 1STH-FRL-4H-245-M60BLK, maximum power $P_{\max }=243.412 \mathrm{~W}$; open circuit
[17] Alizadeh, M., Kojori, S.S. "Small-signal stability analysis and predictive control of Z-Source Matrix Converter feeding a PMSGWECS", International Journal of Electrical Power \& Energy Systems, 95, pp. 601-616, 2018. https://doi.org/10.1016/j.ijepes.2017.09.018

[18] Karaman, E., Farasat, M., Trzynadlowski, A.M. "A Comparative Study of Series and Cascaded Z-Source Matrix Converters", IEEE Transactions on Industrial Electronics, 61(10), pp. 5164-5173, 2014. https://doi.org/10.1109/tie.2014.2301766

[19] Khosrogorji, S., Ahmadian, M., Torkaman, H., Soori S. "Multiinput $\mathrm{DC} / \mathrm{DC}$ converters in connection with distributed generation units-A review", Renewable and Sustainable Energy Reviews, 66, pp. 360-379, 2016. https://doi.org/10.1016/j.rser.2016.07.023

[20] Reddi, N. K., Ramteke, M. R., Suryawanshi, H. M., Kothapalli, K., Gawande, S. P. "An Isolated Multi-Input ZCS DC-DC FrontEnd-Converter Based Multilevel Inverter for the Integration of Renewable Energy Sources", IEEE Transactions on Industry Applications, 54(1), pp. 494-504, 2018. https://doi.org/10.1109/tia.2017.2753160

[21] Kardan, F., Alizadeh, R., Banaei, M. R. "A New Three Input DC/DC Converter for Hybrid PV/FC/Battery Applications", IEEE Journal of Emerging and Selected Topics in Power Electronics, 5(4), pp. 1771-1778, 2017. https://doi.org/10.1109/jestpe.2017.2731816

[22] Rani, P.H., Navasree, S., George, S., Ashok, S. "Fuzzy logic supervisory controller for multi-input non-isolated DC to DC converter connected to DC grid", International Journal of Electrical Power \& Energy Systems, 112, pp. 49-60, 2019. https://doi.org/10.1016/j.ijepes.2019.04.018

[23] Faraji, R., Adib, E., Farzanehfard, H. "Soft-switched non-isolated high step-up multi-port DC-DC converter for hybrid energy system with minimum number of switches", International Journal of Electrical Power \& Energy Systems, 106, pp. 511-519, 2019. https://doi.org/10.1016/j.ijepes.2018.10.038

[24] Mazouz, L., Zidi, S. A., Hafaifa, A., Hadjeri, S., Benaissa, T. "Optimal Regulators Conception for Wind Turbine PMSG Generator Using Hooke Jeeves Method", Periodica Polytechnica Electrical Engineering and Computer Science, 63(3), pp. 151-158, 2019. https://doi.org/10.3311/ppee.13548

[25] Prasad, H., Maity, T. "Z-Source Inverter Based Motor Drives for Industrial Medium Voltage Application", Periodica Polytechnica Electrical Engineering and Computer Science, 59(2), pp. 30-35, 2015. https://doi.org/10.3311/ppee.8121

[26] Peng, F.Z. "Z-source inverter", IEEE Transactions on Industry Applications, 39(2), pp. 504-510, 2003. https://doi.org/10.1109/tia.2003.808920

voltage $V_{o c}=38.3 \mathrm{~V}$; short-circuit current $I_{s c}=8.81 \mathrm{~A}$; voltage at maximum power point $V_{m p}=30.2 \mathrm{~V}$; current at maximum power point $I_{m p}=8.06 \mathrm{~A}$; cells per module $N_{\text {cell }}=60$; parallel strings $N_{p}=150$; series-connected modules per strings $N_{s}=18$.

DIZIMC switching frequency: $f_{s}=5 \mathrm{kHz}$.

Grid parameters: 332/575V $50 \mathrm{~Hz}$. 